\title{
Desafios educacionais nas fronteiras da democracia: aprender com a reexistêneia dos povos ancestrais de Abya Yala
}

\author{
Educational challenges at the borders of \\ democracy: leaning from the re-existence of \\ ancestral peoples of Abya Yala
}

\section{Reinaldo Matias Fleuri*}

Recebido em: 03/11/2021. Aceito em: 25/11/2021.

Resumo: Os riscos iminentes do colapso ecológico global, de uma guerra nuclear e de erosão dos regimes políticos democráticos, baluartes de defesa da sustentabilidade e da paz, evidenciam a urgência de superar radicalmente as fronteiras de exclusão mantidas pelo sistema mundo colonial capitalista, hoje em profunda crise. A insurreição dos movimentos populares de raízes ancestrais promove, rizomática e serpentinamente, processos de reconstituição do Bem Viver, cultivando relações de reciprocidade, complementaridade e integralidade entre os seres e sistemas constitutivos de vida em plenitude. Com os povos originários (particularmente os povos indígenas, quilombolas, tradicionais) aprendemos a desconstruir as necropolíticas - expressas e alimentadas pelo racismo, machismo, patriarcalismo, especismo, capitalismo, colonialismo - mediante as opções e ações radicais, persistentes e cotidianas de decolonizar as estruturas de conexão entre os seres humanos e os ecossistemas. O artigo reflete sobre contribuições que diferentes pesquisadores e pesquisadoras desenvolvem no sentido de promover a decolonialidade do ser e do viver através de práticas educacionais no campo das relações étnicas e de gênero.

Palavras-chave: Democracia. Fronteiras de exclusão. Bem Viver. Povos ancestrais. Decolonialidade. Religião.

* Doutor em Educação (Universidade Estadual de Campinas, UNICAMP, Campinas, SP, 1988). Mestre em Filosofia e História da Educação (Pontifícia Universidade Católica de São Paulo, PUC-SP, São Paulo, SP, 1978). Graduado em Filosofia (Faculdade Nossa Senhora Medianeira - Faculdades Anchieta de São Paulo, FASP, São Paulo, SP, 1971). Professor e pesquisador da Universidade Federal de Santa Catarina (UFSC). Professor visitante nacional sênior na Universidade do Estado do Pará (UEPA/CAPES).

E-mail: rfleuri@gmail.com. 


\begin{abstract}
The imminent risks of global ecological collapse, nuclear war and erosion of democratic political regimes, strongholds for the defense of sustainability and peace, highlight the urgency of radically overcoming the boundaries of exclusion maintained by the colonial capitalist world system, today in deep crisis. The insurrection of popular movements with ancestral roots promotes, rhizomatically and serpentinely, processes of reconstitution of the Good Living, cultivating relationships of reciprocity, complementarity and integrality between beings and constitutive systems of life in full. With the original peoples (particularly indigenous peoples, quilombolas, traditional ones) we learned to deconstruct necropolitics - expressed and fueled by racism, machismo, patriarchy, speciesism, capitalism, colonialism - through radical, persistent and everyday options and actions to decolonize structures connection between humans and ecosystems. The article reflects on the contributions that different researchers and researchers develop towards promoting the decoloniality of being and living through educational practices in the field of ethnic and gender relations.
\end{abstract}

Keywords: Democracy. Exclusion borders. Well Living. Ancestral peoples. Decoloniality. Religion.

\title{
Introdução
}

\author{
He yama yo ${ }^{1}$ \\ Estamos aquí, en el ahora, \\ Estamos aquí, en el eterno presente; \\ $Y$ en todos lados \\ Somos Uno y somos Todo.
}

A Campanha da Fraternidade 2022, ao retomar o tema "Fraternidade e Educação", já priorizado em 1982 e 1998, assume o desafio que o mundo e o Brasil enfrentam hoje: "redescobrir caminhos para uma reconstrução global [...] que deve chegar à raízes do modo como pessoas e povos compreendem e organizam a totalidade da vida"2.

1 He yama yo - Canto Lakota (significado adaptado por despojosdeoccidente.org)

He yama yo wanna henne yo

He yama yo wanna henne yo

Wahi hi yayhana he he he ho

Wahi he he he ho wahi

Disponível em: https://www.youtube.com/watch?v=E3q0uKKZCVM. Mario Gosálvez-Blanco. Música extraida do CD Audio "Nanas para Despertar" Canta: Paky Gomez Coros: (El Coro/Vocerío mas alegre, amoroso y jovial que nadie pueda tener): Antonella Soundshui, Águeda Benavent, Carmen García, David Smy, Francisco Urbina, Laura Palma y Sara Vazquez. Arreglos música: Mario Gosálvez Blanco Video creación: Eugenio López.

2 CNBB - Conferência Nacional dos Bispos do Brasil. Campanha da Fraternidade 2022. Texto-Base. Brasília, Edições CNBB, 2021. p. 7. 
Neste espírito, aprendemos com o hino Lakota, He yama yo, a agradecer por estar no eterno presente, experimentando todos os ciclos da vida: nascer, crescer, regressar à terra para renascer. E auguramos que as mudanças profundas que estão ocorrendo hoje - globalmente em todas as dimensões - nos eduquem para a promoção da criação de oportunidades de vida em plenitude para todas as pessoas e seres que constituem nosso ecossistema, nossa "Mãe Natureza". Desejamos que todos os povos, todas as culturas, todas as epistemologias, todos os saberes, todas as formas de vida e de relação sejam valorizadas e fluidamente interconectadas.

Mas, para que cenários futuros mais humanizados e mais plenos de vida sejam possíveis, precisamos reconhecer e superar as fronteiras de exclusão que emergem de modo articulado em nossas regiões, em nossos continentes. E nos situamos no continente de Abya Yala que, mesmo colonizado sob o nome genérico de "América", contém a diversidade e potencialidade de infinitas formas de vida e culturas humanas e naturais.

Estes desejos profundos se defrontam com impasses ambientais e políticos em que a humanidade hoje se encontra. Noam Chomsky ${ }^{3}$ denuncia a configuração iminente de três desafios fatais para toda a humanidade hoje. Primeiro, o risco iminente do colapso ecológico global, pela ação predatória do sistema econômico global que hoje está dominando o planeta. Segundo, o risco de uma guerra nuclear, que vem sendo armada sorrateira e decididamente pelas grandes potências econômicas e políticas, em disputa pelos territórios. Terceiro, o risco da destruição dos regimes políticos democráticos, baluartes de defesa da sustentabilidade e da paz.

A reinvenção da democracia se torna urgente e estratégica, para superar as fronteiras de exclusão que minam a solidariedade e a harmonia entre todos os seres da natureza.

Neste sentido, gostaria de retomar e discutir no presente artigo o que tenho aprendido com lideranças e intelectuais orgânicos de movimentos populares de raízes ancestrais, que vêm intensificando sua participação protagonista em muitos eventos, que estrategicamente vêm se proliferando no mundo da comunicação virtual, como o que ocorreu no IX Seminário Internacional: Fronteiras Étnico-Culturais e Fronteiras da

3 EATON, George. Noam Chomsky: The world is at the most dangerous moment in human history. New Statesman. 17 September 2020. Disponível em: https://www. newstatesman.com/world/2020/09/noam-chomsky-world-most-dangerous-moment-human-history. Acesso em: 22 nov. 2021. 
Exclusão, realizado de 28 a 30 de outubro de $2020^{4}$. Assim, neste artigo aprofundarei a reflexão sobre o debate realizado nesse acontecimento, como um exercício de educação popular, no sentido de promover processos de reinvenção e de reconstrução das democracias, que desativem os dispositivos de exclusão e potencializem as fronteiras de "conexão", geradoras de vida e convivência em plenitude entre todos os seres que constituem o cosmos, nossa casa comum.

\section{Fronteiras de exclusão}

A pesquisadora afro-colombiana Anny Ocoró Loangó ${ }^{5}$ menciona, em sua conferência de abertura do evento, quatro fronteiras de exclusão predominantes hoje na sociedade e que nos desafiam a reinventar a democracia.

A primeira fronteira emerge nas lutas para se estabelecer relações de igualdade de direitos e oportunidades entre os diferentes povos e grupos sociais. As fronteiras de desigualdades sociais têm sido importantes campos de lutas na América Latina. Intensificaram-se as lutas dos povos indígenas e quilombolas, assim como dos povos tradicionais, pelo reconhecimento de suas identidades e de suas autonomias étnicas. Conseguiram mudanças constitucionais importantes em todos os países. No Brasil, a Constituição de 1988 reconhece a identidade dos povos indígenas e institui medidas de proteção desses povos. No entanto esses povos continuam enfrentando sérias desigualdades estruturais históricas nas relações econômicas, de gênero, étnico-culturais, territoriais e mesmo na ação social, econômica e política. Os afro-indígenas, sujeitos ao racismo e à discriminação institucionalizada, enfrentam desigualdades territoriais no acesso à água, nas oportunidades de trabalho e de

4 FLEURI, Reinaldo Matias, 30 de outubro de 2020. Interseccionalidade raça/etnia, gênero e classe como estratégia democrática e de análise científica das fronteiras étnico-culturais e da exclusão. In: IX SEMINÁRIO INTERNACIONAL: FRONTEIRAS ÉTNICO-CULTURAIS E FRONTEIRAS DA EXCLUSÃO [WEBINAR]. Campo Grande (MS): Universidade Católica Dom Bosco. Conferência de Encerramento. Disponível em: https://youtu.be/0v3FNezP6i8. Acesso em: 22 nov. 2021.

5 LOANGÓ, Anny Ocoró (CONICET-UNTREF). Diferença, democracia e resistência no contexto das fronteiras étnico-culturais e da exclusão. In: IX SEMINÁRIO INTERNACIONAL: FRONTEIRAS ÉTNICO-CULTURAIS E FRONTEIRAS DA EXCLUSÃO, 9, Campo Grande (MS), WEBINAR - IX Seminário Internacional: Fronteiras Étnico-Culturais e Fronteiras da Exclusão. Conferência de Abertura (28/10/2020). Campo Grande: UCDB, 2020. Disponível em: https://youtu.be/_yZNKSWUZ_s . Acesso em: 22 nov. 2021. 
sustentação econômica, no acesso aos serviços de saúde, principalmente no nosso contexto atual de pandemia.

A segunda classe de fronteiras se refere às relações de superioridade-inferioridade estabelecidas entre o humano e não-humano. A modernidade ocidental, com sua cosmovisão antropocêntrica, justifica o especismo (a superioridade da espécie humana sobre todas as outras espécies de seres vivos), o racismo (a naturalização da dominação de um grupo social sobre outro) e o patriarcalismo (o pátrio-poder masculino sobre todos os seres vivos e não vivos que compõem seu domínio). Estas estruturas relacionais se consolidam no processo histórico de conquista e colonização do continente "americano" pelas elites econômico-políticas europeias ou europeizadas. Não obstante as sucessivas mudanças sociais e políticas na organização dos diferentes Estados e povos, a colonialidade permanece através de padrões socioculturais especistas, racistas e patriarcais.

As fronteiras racistas foram consolidadas pelo estado nacional que, no seu processo de expansão imperial e colonial, nega e combate as raízes afro-indígenas dos povos escravizados, subalternizados ou expulsos de seus territórios. O racismo hierarquiza as diferenças e legitima desigualdades.

O terceiro tipo de fronteiras são as dos territórios e das culturas. Essas fronteiras são impulsionadas pelos Estados - e pelas corporações econômicas que os controlam - com o propósito de ocupar, explorar, expropriar os recursos naturais e humanos, transformando-os em produtos a serviço do mercado global, em benefício da acumulação de riquezas e poder sob o controle de poucas e centralizadas corporações multinacionais. Com isso, se comete um eco-etnocídio, ao desterritorializar violentamente as comunidades dos povos indígenas, quilombolas, tradicionais, todas as comunidades populares. A necropolítica, que se volta contra os seres humanos, contra o pluralismo das suas epistemologias e dos seus territórios, amplia-se contra a autonomia e preservação de todos os seres da natureza. É aqui que se colocam as fronteiras do especismo. Que considera a espécie humana como superior a todas outras espécies de seres vivos, com direito de dominá-las e explorá-las, independentemente de seus sentimentos e impulsos vitais.

O quarto âmbito de fronteiras é o do autoritarismo, que se escancarou hoje em nível global. Direitos conquistados pelos povos estão retrocedendo nas políticas sociais, pela ação virulenta de movimentos ultraconservadores fundamentalistas que buscam, ardilosa e violentamente, 
eliminar os diferentes e todos aqueles que são vistos como opositores a essa visão autoritária. A manutenção e potencialização dos discursos de ódio e de exclusão, que negam a possibilidade de existência dos diferentes, tornam a construção da democracia uma luta árdua, profunda e urgente.

O autoritarismo, a necropolítica, o especismo, o racismo, as desigualdades sociais minam as lutas e conquistas democráticas e colocam desafios existenciais urgentes para toda humanidade e para toda forma de vida em nosso planeta.

\section{A crise global e processos de reexistência}

Vivemos hoje uma situação de impasse global que lembra o apocalipse. Este é o fim do sistema-mundo moderno colonial, que se segue a muitos outros finais de civilizações, muitas delas aniquiladas pelas próprias conquistas coloniais e imperiais, como o que ocorreu com a maioria dos povos originários do continente de Abya Yala.

Entretanto descendentes de povos originários extintos ou sobreviventes hoje resistem e reexistem. As lutas de reexistência dos povos originários ancestrais nos proporcionam um ponto de vista alternativo determinante, para interpretarmos e enfrentarmos a crise apocalíptica que hoje estamos vivendo.

O sistema-mundo colonial capitalista global está em profunda crise. Em agonia, diria! Pois, na busca de acumular riqueza e poder sob controle de algumas poucas corporações, suas contradições estão se acirrando e promovendo profundas desarticulações, que tornam insustentável a manutenção das lógicas de dominação, de exploração, de imposição e de destruição de todas as diferentes formas de vida.

Tal crise está sendo impulsionada pela emergência dos movimentos sociais, ligados a culturas ancestrais, que estão construindo já de longa data seus processos de reexistência. É muito mais do que "resistência", muito mais do que a preservação e manutenção de suas identidades ou de combate aos opositores.

Flávia Schilling, em sua tese Estudos sobre resistência ${ }^{6}$, diz que a resistência pode ter diferentes significados. Considerando a raiz latina do

6 SCHILLING, Flavia Ines. Estudos sobre resistência. 1991. 257 f. Dissertação (Mestrado) - Universidade Estadual de Campinas, Faculdade de Educação, Campinas, SP. 
termo sustere, significa sustentar pela oposição (re-): como uma estaca que, opondo-se a uma parede, a mantém em sua posição. Entendida como simples oposição (re-sustere), a resistência acaba por sustentar o processo que combate. Já o verbo latino sistere significa se posicionar em pé ou firmar alguma coisa. Assim, etmologicamente, e-sistere, sugere afirmar-se e crescer de dentro para fora, desenvolver-se autonomamente. Re-sistere, implica em se reerguer frente a lutas, a derrotas, a quedas, a processos de morte. Re-e-sistere significaria reviver e se educar autonomamente, a partir das próprias raízes ancestrais, conectando-se com a vitalidade de todos os seres do universo. Neste sentido, a re-existência implica em re-surgir a partir de algo firme, autêntico, potente e autônomo. Este é o movimento vital, que não se limita a opor-se aos que nos ameaçam. Trata-se de criar ou reconstituir estruturas de conexões equilibradas, harmoniosas e fluidas entre os seres, que realimentem sua vitalidade singular e sistêmica. Reexistir, portanto, implica em viver, reviver, conviver e gerar vida em plenitude ${ }^{7}$.

Lembro o que me dizia pessoalmente Eliel Benites ${ }^{8}$ em 2002, durante o Primeiro Seminário de Fronteiras Étnico-Culturais, em Campo Grande: "os povos Kaiowá-Guarani promovem uma educação que parte da comunidade e do empoderamento de cada pessoa. A educação é, pois, como destapar uma fonte de água pura, que jorra em abundância". Assim, educar é promover esse processo de crescimento, de evolução, de vida, a partir de sua busca existencial de si mesmo, de dentro para fora, conectando-se dinamicamente, a partir das próprias ancestralidades, com todos os seres do universo. Trata-se de um processo de reconstituição de estruturas de conexão, de vida, que vêm sendo geradas, cultivadas pelos povos originários ancestrais, portadores dessa sabedoria.

\section{Vida em plenitude}

Para os povos originários ancestrais, o desenvolvimento da vida de cada pessoa só se configura na relação com todos os outros seres

Disponível em: https://doi.org/10.47749/T/UNICAMP.1991.33204; http://www.repositorio. unicamp.br/Busca/Download?codigoArquivo=457123. Acesso em: 3 nov. 2021.

7 FLEURI, Reinaldo Matias. Paulo Freire e as cosmovisões dos povos originários. In: Educazione Aperta, v. 7, 2020b, p. 242-261. Disponível em: https://educazioneaperta. it/archives/2828. Acesso em: 12 out. 2021.

8 Eliel Benites é da etnia Kaiowáa Guarani, Mestre em Educação pela Universidade Católica Dom Bosco (2014) e Doutor em Geografia pela Universidade Federal da Grande Dourados (2021). 
que constituem o universo. A grande Mãe Terra (Gaia, Pachamama) é constituída pela convivência harmoniosa entre todos os seres vivos, dotados de autonomia, desde as diferentes "espécies" de seres animais e vegetais, até os sistemas galácticos ou infra-atômicos. Também as forças da natureza, que as culturas ancestrais simbolizam com as forças do fogo, da terra, do ar e da água. Cada elemento, com diferentes potenciais e lógicas de criação e geração de vida. E é pela relação de oposição-complementaridade dessas forças que se produz a dinâmica evolutiva de geração de equilíbrio, reequilíbrio de vida, de circulação fluente de energias entre todos os seres.

A evolução dos processos vitais é impulsionada autonomamente, de dentro para fora, mas se constitui na conexão estrutural, radical, com todos os seres vivos. Essas relações são mesmo de oposição, mas também de composição, de transposição, de reposição, de imposição, de suposição... Enfim, são relações complexas de contraditoriedade e complementaridade entre todos os seres. Complementaridade que se ativa e se alimenta pela reciprocidade.

As diferenças entre forças que se opõem e se compõem são essenciais, na medida em que geram e alimentam a reciprocidade. É o que se aprende com as culturas ancestrais. A concepção do Bem-Viver ("Buen-Vivir", "Sumak Kawsay"), formulada por teóricos de povos originários Quechua e Aimara, explicita esses princípios".

Na perspectiva insurgente das culturas dos povos originários ancestrais - com seus saberes, com suas relações de poder, seus modos de ser e de viver - as fronteiras étnico-culturais, assim como todas as fronteiras, podem superar o caráter de exclusão ou sujeição produzido pelo sistema-mundo colonial e se potencializarem como entre-lugares - diria Homi Bhabha ${ }^{10}$ - espaços de enunciação e de criação de vida em plenitude.

Em suma, as fronteiras de exclusão ou de inclusão assimilatória podem ser subvertidas em fronteiras de conexão, de reciprocidade, de interculturalidade, de interseccionalidade, em que todas as diferenças e as oposições constituem relações de vida em plenitude, na medida em que se conectam com todas as formas diferentes de vida. Então, preservar as diferenças, construir as diferenças, alimentar as diferenças é ativar

9 FLEURI, Reinaldo Matias. Paulo Freire e as cosmovisões dos povos originários. In: Educazione Aperta, v. 7, 2020b, p. 242-261. Disponível em: https://educazioneaperta. it/archives/2828. Acesso em: 2 out. 2021.

10 BHABHA, Homi. O local da cultura. Belo Horizonte: UFMG, 1998. 
relações de reciprocidade e de complementaridade entre opostos, e entre cada ser singular com os contextos sistêmicos em que se constituem.

\section{Aprender com os povos ancestrais}

Estamos aprendendo com os povos e as culturas ancestrais a desconstruir as lógicas coloniais de sujeição, de subalternização, de exclusão e de dominação.

As culturas e os saberes ancestrais são epistêmica e eticamente complexos, densos, críticos, criativos e potentes, capazes de responder aos desafios radicais e globais decorrentes da civilização moderno-colonial.

Os povos originários e tradicionais - que normalmente são vistos desde a ótica do sistema-mundo colonial como marginais, primitivos, inferiores, incapazes - na realidade, produzem saberes científicos segundo lógicas diferentes, mais consistentes e complexas do que as lógicas das ciências modernas ocidentais. Reconhecer a cientificidade, a consistência e a potência desses saberes dos povos originários - tal como o fez José Licínio Backes, ao introduzir a apresentação de Loangó ${ }^{11}$ - é um passo de crescimento que estamos realizando no mundo da academia e das universidades.

Nossa sociedade organizada politicamente como Estado-Nação, é muito rígida, na medida em que reconhece apenas uma língua, apenas uma identidade étnica, uma religião monoteísta, uma cultura padrão. Não consegue compreender, nem interagir de uma maneira criativa com os outros saberes, com os outros pontos de vista, com os outros sujeitos sociais coletivos.

Reconhecer a cientificidade dos saberes dos povos originários, os saberes populares ancestrais, é um salto de qualidade na nossa forma de pensar, na nossa forma de produzir conhecimento.

No continente ameríndio, os afrodescendentes - mesmo que atravessando processos históricos de cruel violência colonial, escravocrata,

11 LOANGÓ, Anny Ocoró (CONICET-UNTREF). Diferença, democracia e resistência no contexto das fronteiras étnico-culturais e da exclusão. In: IX SEMINÁRIO INTERNACIONAL: FRONTEIRAS ÉTNICO-CULTURAIS E FRONTEIRAS DA EXCLUSÃO, 9, Campo Grande (MS), WEBINAR - IX Seminário Internacional: Fronteiras Étnico-Culturais e Fronteiras da Exclusão. Conferência de Abertura (28/10/2020). Campo Grande: UCDB, 2020. Disponível em: https://youtu.be/_yZNKSWUZ_s. Acesso em: 22 nov. 2021. 
patriarcal e racista - trouxeram, conservaram, multiplicaram, resistiram, reexistiram e revitalizaram princípios complexos originários de suas culturas. E os traduzem cotidianamente em suas práticas cotidianas, nos seus modos de ser, de interagir em família, nas suas linguagens, nas suas artes, nas suas expressões culturais as mais diversas. Sobretudo nas suas práticas religiosas, que se religam cotidianamente e profundamente com suas raízes ancestrais.

As culturas originárias africanas trazem princípios que se articulam com os princípios das culturas dos povos originários de Abya Yala. Ubuntu, por exemplo, é um termo Zulu que indica o próprio conceito de Humanidade, entendendo que o ser de cada pessoa está intimamente conectado ao ser dos outros e da comunidade: "Sou, porque somos" (definição realizada por Leymah Gbowee, ativista pacifista da Libéria). Este mesmo princípio é constitutivo da concepção andina do "Bem Viver".

\section{Vencer as necropolíticas}

O grande desafio hoje é o de reexpressar e ressuscitar, de dar vida às conexões radicais ancestrais em que cada um de nós se constitui como pessoa e como comunidade. Ao viver e ao conviver em plenitude, cada um de nós se torna fonte geradora de Bem Viver subvertendo sistemicamente as lógicas das necropolíticas que, como as grandes muralhas, desmoronam pelo crescimento das pequenas ervas vivas em suas fissuras.

Não se trata de meramente se opor, nem de se submeter às necropolíticas. Trata-se de revitalizar nossas conexões radicais, com as raízes de nossas culturas, epistemologias e estruturas de poder ancestrais, potencializando as nossas formas de viver e de gerar vida em plenitude. Ao alimentar e gerar formas de convivência em plenitude, pela dinâmica de reciprocidade, complementaridade e integralidade, superamos a atitude de apenas "tolerar" o oposto. Frente às agressões mobilizadas pelo ódio, medo ou crueldade, tão explícitas nos dias de hoje, podemos responder insurrecionalmente, energicamente, autenticamente, criativamente, generosamente, potencializando princípios e opções geradoras de vida e de transformação radical das estruturas e das estratégias necrofílicas.

Neste caminho, podemos encontrar uma potente parceria com os movimentos populares de raízes ancestrais, ao reconhecer o protagonismo e o valor das pessoas, dos grupos, das comunidades, dos povos que buscam conviver e gerar vida em plenitude. Mediante suas lutas decoloniais 
de reexistência, se apresentam como a(u)tores e protagonistas da história e não como vítimas passivas do sistema mundo moderno-colonial (o qual insiste em considerá-los negativamente como "inferiores, primitivos, marginais, excluídos, oprimidos...", como carentes e necessitados da ação "civilizatória" e "salvacionista", que mascara a violência das invasões e guerras coloniais).

\section{Decolonizar mentes}

Durante a palestra de Luiz Henrique Eloy Amado (APIB), advogado Terena, que discutiu a Contribuição de Pesquisas de Indígenas e com Indígenas ${ }^{12}$, perguntei-lhe sobre as estratégias que os povos indígenas estão construindo para vencer o colonialismo e o racismo. Eu queria entender como buscam construir a sua hegemonia na sociedade brasileira para promover transformações radicais, justamente nessa perspectiva de Viver em Plenitude.

Eloy contestou a ideia de hegemonia que passei nessa pergunta. Afirmou que os povos indígenas não têm o objetivo de conquistar a hegemonia, o controle dos outros grupos sociais para manter uma supremacia sobre eles. Porque a sociedade é pluriétnica e o Estado deve respeitar as diferentes formas de vida e de convivência. As lutas dos povos indígenas não visam adquirir a supremacia na sociedade brasileira, mas sim cultivar os territórios ancestrais, em que cada povo, seguindo suas tradições, possa viver em plenitude e conviver com os diferentes, respeitando e promovendo suas diferentes formas de Bem Viver.

Tal posição implica em decolonizar a nossas mentes.

"Mente", segundo Gregory Bateson ${ }^{13}$, significa as estruturas de conexão entre os seres vivos. Decolonizar a mente implica em desconstruir as lógicas de dominação, em que o indivíduo busca se afirmar mediante a negação dos outros indivíduos e a sujeição dos elementos

12 AMADO, Luiz Henrique Eloy (APIB). A Contribuição de Pesquisas de Indígenas e com Indígenas. In: IX SEMINÁRIO INTERNACIONAL: FRONTEIRAS ÉTNICO-CULTURAIS E FRONTEIRAS DA EXCLUSÃO, 9, Campo Grande (MS), WEBINAR - IX Seminário Internacional: Fronteiras Étnico-Culturais e Fronteiras da Exclusão. Mesa-Redonda - Diferença, Democracia e Resistência: A Contribuição das Pesquisas Acadêmicas (30/10/2020). Campo Grande: UCDB, 2020. Disponível em: https://youtu. be/ImTqcmJfFjs . Acesso em: 10 out. 2021.

13 BATESON, G. Mente e Natureza. A unidade necessária. Trad. bras. Claudia Gerpe. Rio de Janeiro: Francisco Alves, 1986. 
da natureza. Decolonizar não significa destruir "a pessoa" identificada com as práticas de colonização, mas reconstruir as relações entre as pessoas, potencializando as lógicas de Vida em Plenitude que, por sua complexidade, superam as lógicas de oposição binária constitutivas da colonialidade. Cada ser, de fato, só mantém sua vitalidade singular, autocriativa, evolutiva, mediante a recriação constante de estruturas relacionais de complementaridade, reciprocidade e integralidade em sua interação com todos os seres da natureza e com seus parentes humanos.

\section{0 mais íntimo e sublime}

A decolonização das nossas mentes, ou seja, a ativação das estruturas relacionais que potencializam as conexões fluentes entre todos os seres vivos, passa por processos íntimos, pessoais, singulares, vividos por cada um e cada uma de nós.

Dinamara Feldens, ao discutir a Contribuição das Pesquisas de Gênero $^{14}$, narra sua experiência pessoal de pesquisa no contexto de rituais Fulni-ô, que lhe permitiu ressignificar sua consciência de mulher e de mãe ao se reconectar com seus ancestrais.

A pesquisadora decide tomar seu próprio corpo de mulher e de mãe, como experiência de produção do conhecimento, sobre o ser mulher e o ser mãe, no atual contexto patriarcal e machista da sociedade ocidental. Feldens mostra como ela aprendeu, pela experiência no contexto cerimonial dos povos indígenas, novas significações do ser mulher e de reexistir como mãe.

Essa experiência espiritual indica a potência epistêmica de produção de conhecimento fundada ancestralmente. Pois, ao possibilitar a ressignificação e potencialização do feminino e da maternidade articulada com a vida da natureza como um todo, a experiência espiritual ensejada no contexto ritual vai desconstruindo de dentro para fora a colonialidade, o machismo, o patriarcalismo. E evidencia que cada pessoa pode vivenciar esse processo de existência e reexistência, ao realizar um mergulho profundo em si mesma, na busca pela conexão com suas raízes ancestrais.

14 FELDENS, Dinamara (UFS). A Contribuição das Pesquisas de Gênero. In: IX SEMINÁRIO INTERNACIONAL: FRONTEIRAS ÉTNICO-CULTURAIS E FRONTEIRAS DA EXCLUSÃO, 9, Campo Grande (MS), WEBINAR - IX Seminário Internacional: Fronteiras Étnico-Culturais e Fronteiras da Exclusão. Mesa-Redonda - Diferença, Democracia e Resistência: A Contribuição das Pesquisas Acadêmicas (30/10/2020). Campo Grande: UCDB, 2020a. Disponível em: https://youtu.be/ImTqcmJfFjs. Acesso em: 10 out. 2021. 
A reflexão da pesquisadora Dinamara Feldens lembra Sócrates, para quem buscar a sabedoria implica primordialmente em "conhecer a si mesmo" ${ }^{15}$. Nas perspectivas culturais dos povos originários, conhecer a si mesmo implica em conectar-se com as próprias origens, com os próprios ancestrais, cujos valores profundos cada pessoa traz na própria intimidade, a qual se conecta com o todo, com o que Santo Agostinho chamaria de "divino". Em Confissões, Santo Agostinho relata sua busca por entender e se conectar com Deus, que podemos entender filosoficamente como o princípio articulador da vida, da fluidez e da coesão entre todos os seres, com as dimensões relacionais que constituem a harmonia do cosmos. Agostinho descobre que Deus, fonte geradora de vida, é "mais íntimo que o meu próprio íntimo e mais sublime que o ápice de meu ser!"16.

O individualismo, paradoxalmente, se desconstrói mediante a reconexão íntima de cada pessoa com o seu ser profundo, que se conecta no presente com todos os seres da natureza, com todos seus ancestrais e descendentes. Nisso consiste a dimensão espiritual! A nosso ver, Gregory Bateson, ao definir "Espírito" ou "Mente" como "estrutura que coliga" 17 , se refere às conexões que cada ser vai tecendo em interação com todos os outros seres, que constituem, de modo complexo e comunitário, o contexto vital integral que, por sua vez, gera e alimenta a singularidade da vida de cada ser.

\section{Religião e colonialidade}

Eloy Terena apresenta as lutas que as comunidades indígenas estão desenvolvendo frente às práticas coloniais exercidas particularmente por escolas e por igrejas missionárias. Hoje, como outrora, organizações religiosas ocidentais, com aparato tecnológico e poderosos recursos financeiros se imiscuem nas comunidades originárias, convencendo-as a assimilar princípios religiosos estranhos às suas culturas, minando os modos de vida e a coesão da vida do povos indígenas.

15 A frase "conhece-te a ti mesmo", atribuída ao filósofo grego Sócrates (479-399 a.C.), é de fato a inscrição que se via na entrada do Oráculo de Delfos, dedicado a Apolo (na mitologia grega, o deus da luz e do sol, da verdade e da profecia). Na filosofia socrática o "conhece-te a ti mesmo" é o principio que orienta a busca do conhecimento do mundo com base no autoconhecimento. Conhecer-se é considerado como o ponto de partida para uma vida equilibrada e, por consequência, mais autêntica e feliz.

16 AGOSTINHO. Confissões. Trad. de J. Oliveira Santos, S.J. e A. Ambrósio de Pina, S.J, 1. ed. São Paulo: Victor Civita, 1973. p. 63 (Livro III, Capitulo 6, seção 11). Coleção Os Pensadores, vol. VI.

17 BATESON, G. Mente e Natureza. A unidade necessária, p. 19. 
A denúncia da Articulação dos Povos Indígenas do Brasil (APIB), reportada por Eloy Terena ${ }^{18}$, reverbera o relato de Dom Samuel Ruiz Garcia, bispo de Chiapas, em sua palestra realizada em 1983, na PUC de São Paulo: "O missionário quase sempre chega com dois tipos de prepotência, ou ideias falsas. Primeiro: a de que sua cultura é superior à do povo que vai evangelizar e, segundo, a de que a sua religião é mais verdadeira e, por isso, a única que tem direito de se expressar e existir. Por consequência, o processo de evangelização tem consistido em um processo de destruição de culturas" 19 .

Os missionários que trabalhavam com o bispo Samuel Ruiz Garcia começaram a perceber que a catequese que eles traziam gerava um certo conflito com essas comunidades. Que, ao invés de empoderar a autonomia dessas comunidades, promovia desarticulação da sua capacidade criativa e de resistência. E perguntaram a um antropólogo sobre o papel da religião nas culturas ancestrais. Ao que o pesquisador respondeu: "Em todas as culturas que eu conheço, a religião é um ponto fundamental, essencial, aglutinante de todos os fatores" ${ }^{20}$. Compreenderam que a religião constitui um núcleo articulador e vital de coesão de uma comunidade, que lhe possibilita, portanto, viver, existir, e resistir frente aos ataques coloniais.

Por isso, a catequização missionária que desrespeita as culturas e as religiões ancestrais, ou as desqualifica como "superstições", produz um efeito de subalternização, de dominação, de exclusão, de destruição desses povos. É justamente esta a intenção estratégica do colonialismo, do capitalismo globalizado atual, que está sendo promovido por grandes corporações multinacionais estabelecidas no sistema econômico nacional. O relatório da Articulação dos Povos Indígenas do Brasil e Amazon Watch $^{21}$ "mostra que companhias que representam os três principais setores

18 AMADO, Luiz Henrique Eloy (APIB). A Contribuição de Pesquisas de Indígenas e com Indígenas. In: IX SEMINÁRIO INTERNACIONAL: FRONTEIRAS ÉTNICO-CULTURAIS E FRONTEIRAS DA EXCLUSÃO, 9, Campo Grande (MS), WEBINAR - IX Seminário Internacional: Fronteiras Étnico-Culturais e Fronteiras da Exclusão. Mesa-Redonda - Diferença, Democracia e Resistência: A Contribuição das Pesquisas Acadêmicas (30/10/2020). Campo Grande: UCDB, 2020. Disponível em: https://youtu. be/ImTqcmJfFjs. Acesso em: 10 out. 2021.

19 GARCIA, Samuel Ruiz. Igreja e opção pelos pobres. In: FLEURI, Reinaldo Matias (org.). Movimento Popular, Política e Religião. São Paulo: Loyola, 1985. p. 79.

20 GARCIA, Samuel Ruiz. Igreja e opção pelos pobres, p. 80.

21 ARTICULAÇÃO DOS POVOS INDÍGENAS DO BRASIL (APIB); AMAZON WATCH. Cumplicidade na destruição III: como corporações globais contribuem para violações de 
econômicos brasileiros - mineração, agronegócio e energia - estiveram direta ou indiretamente envolvidas em conflitos que afetam os Povos Indígenas e seus territórios".

\section{Estratégias decoloniais ancestrais}

A luta dos povos indígenas por resistir a esses ataques totais e cruéis não é um fato novo. Em nosso continente, os povos originários vêm desenvolvendo há séculos suas lutas com estratégias de ação não lineares. Assumindo metodologias que podem ser indicadas metaforicamente pelo crescimento de um rizoma ou pelo modo sinuoso como a serpente se movimenta, seguindo seus propósitos, observando atentamente o ambiente, contornando os obstáculos, mergulhando e atravessando os diferentes contextos ${ }^{22}$, vão resistindo e se reconstruindo frente a esses ataques maciços da colonialidade. E o atual contexto de pandemia, ao mesmo tempo que escancara contradições e a crueldade do sistema mundo colonial-capitalista, evidencia também as lutas de resistência e de reexistência dos povos originários, que já vem se desenvolvendo de múltiplas formas, em múltiplos contextos, por múltiplos povos e movimentos populares.

Tal como foi, por exemplo, a estratégia dos povos e dos caciques indígenas do Mato Grosso, que há 20 anos decidiram levar seus jovens para se formar nas universidades, para aprenderem as linguagens e os conhecimentos dos brancos, capacitando-se para defenderem seus povos e suas culturas. Hoje, muitos jovens indígenas se tornaram intelectuais orgânicos importantes de suas comunidades. E sua principal luta é defender a autonomia de seus territórios, de suas culturas, de sua espiritualidade, para cultivar as relações de harmonia com a natureza e entre as comunidades que propiciam a vida em plenitude para cada povo.

direitos dos povos indígenas da Amazônia Brasileira. APIB/AW, 2020, p. 4. Disponível em: https://amazonwatch.org/assets/files/2020-cumplicidade-na-destruicao-3.pdf. Acesso em: 27 jul. 2021.

22 WALSH, Catherine et al. Abertura do V Colóquio Internacional Diálogos Sul-Sul: O pensamento decolonial como instrumento de resistência: diferentes olhares. In: $\mathrm{V}$ COLÓQUIO INTERNACIONAL DIÁLOGOS SUL-SUL Y II CONGRESSO INTERNACIONAL DE PESQUISA E PRÁTICAS EM EDUCAÇÃO (CONIPPE), Territórios e Fronteiras de vida em plenitude: desafios, propósitos e articulações atuais de raízes ancestrais. Mesa redonda: Catherine Walsh; Adrian Kethen Picanço Barbosa; Reinaldo Matias Fleuri (23/08/2021, 8h às 22h). TV-UFAC. Disponível em: https://youtu. be/Wfbz3kHKa9w. Acesso em: 10 out. 2021. 


\section{Decolonialidade e relações de gênero}

As lutas dos povos indígenas, representadas por Eloy Terena, têm muito a ver com as lutas dos movimentos socioculturais de reexistência no campo de gênero e sexualidade, discutidas também por Aguinaldo Rodrigues Gomes $^{23}$. O pesquisador relata o histórico das lutas feministas, que se iniciaram com a luta por defender o direito de voto e da cidadania das mulheres, até pouco tempo não reconhecido nas sociedades modernas. Aluta feminista por cidadania se amplia para a construção de autonomia a partir do próprio corpo, mediante as lutas por serem politicamente reconhecidos os direitos do controle do próprio corpo, do prazer, do direito de decidir e de conduzir sua maternidade. E hoje as lutas de gênero buscam o reconhecimento da transversalidade de gênero. Estas lutas, lideradas pelos transgêneros, questionam radicalmente a polaridade excludente entre masculino e feminino, combatendo a padronização homogeneizante do modo de ser pessoa, de viver a sexualidade e a amorosidade. E evidenciam, hoje, que há formas diferentes de se constituir como homem, como mulher ou como terceiro gênero.

Os movimentos por reconhecer as diferentes formas de sexualidade e de gênero questionam uma dimensão epistêmica fundante do colonialismo, que é a polarização e a antagonização das diferenças. Evidenciam, ao invés, que todas as diferentes formas de ser e de viver, de se constituir como pessoas na comunidade, se constituem transversalmente, como conexões fluidas, relacionais, de reciprocidade e complementaridade, e não pela rígida polarização, que induz à exclusão e à sujeição do outro.

Nesse sentido, tais lutas desconstroem a lógica da polarização e do antagonismo, geradora do autoritarismo, do patriarcalismo, do racismo, do machismo, do especismo, do capacitismo, do capitalismo, instituindo e se articulando com outras estratégias de resistências.

\section{Desafios e potencialidades decoloniais no cotidiano}

Os movimentos de luta pela gestão e geração da vida, com suas lutas anti-patriarcais, articulam-se com os movimentos sociais que atuam

23 GOMES, Aguinaldo Rodrigues (UNEMAT). A Perspectiva dos Movimentos de Gênero. In: IX SEMINÁRIO INTERNACIONAL: FRONTEIRAS ÉTNICO-CULTURAIS E FRONTEIRAS DAEXCLUSÃO, 9, Campo Grande (MS), WEBINAR - IX Seminário Internacional: Fronteiras Étnico-Culturais e Fronteiras da Exclusão. Mesa-Redonda - Diferença, Democracia e Resistência: A Perspectiva dos Movimentos Sociais (29/10/2020). Campo Grande: UCDB, 2020. Disponível em: https://youtu.be/Q8OB_mISMNM. Acesso em: 10 out. 2021. 
nos campos étnico-raciais e têm promovido importantes conquistas políticas decoloniais no sentido de superar os estigmas racistas herdados de nossa história escravocrata.

Ahyas Siss ${ }^{24}$ evidencia, entretanto, os riscos de que essas lutas por garantia de oportunidades e direitos iguais para todas as pessoas, independentemente de suas origens étnicas e de suas opções de gênero, sejam capturadas pelas lógicas coloniais do próprio Estado-Nação. O pesquisador observa que as lutas realizadas dentro da instituição escolar, tendem a ser assimiladas à lógica disciplinar de sujeição e de produção de corpos dóceis e produtivos para o mercado.

Por outro lado, Aguinaldo Rodrigues Gomes, anteriormente citado, lembra que os movimentos de resistência e de reexistência, ao mesmo tempo em que correm o risco de assimilação à lógica excludente do sistema disciplinar do Estado e da escola, abrem espaços intersticiais de experiências criativas insurrecionais, tecidas dinamicamente pelas pessoas em interação.

Por isso, as lutas antirracistas, observadas desde a perspectiva das pessoas, grupos e as comunidades que as conduzem, ampliam-se e se multiplicam como cadeias de vida nas experiências cotidianas que, muitas vezes, são invisibilizadas pelo panóptico, pelo olhar que vem de cima para baixo.

Os significados profundos das lutas desenvolvidas pelos movimentos populares não são reconhecíveis desde o ponto de vista exclusivamente jurídico-legal. Mas, sim, desde o ponto de vista dos grupos que, em seu cotidiano, vão tecendo relações geradoras de criatividade, que se expressa nas músicas, nas poesias, nas narrativas, nas lendas, nas descobertas, nos risos e nos choros das pessoas, nos sentimentos e conexões que cada pessoa vai cultivando nas suas interações. E é da ativação cotidiana dessas relações que se produz a exuberância de vida em plenitude, que as diferentes organizações de lutas populares traduzem em transformações institucionais, políticas, econômicas, jurídicas, culturais.

24 SISS, Ahyas (UFRRJ). Perspectiva do Movimento Social Negro. In: IX SEMINÁRIO INTERNACIONAL: FRONTEIRAS ÉTNICO-CULTURAIS E FRONTEIRAS DA EXCLUSÃO, 9, Campo Grande (MS), WEBINAR - IX Seminário Internacional: Fronteiras Étnico-Culturais e Fronteiras da Exclusão. Mesa-Redonda - Diferença, Democracia e Resistência: A Perspectiva dos Movimentos Sociais (29/10/2020). Campo Grande: UCDB, 2020. Disponível em: https://youtu.be/Q8OB_mISMNM. Acesso em 10 out. 2021. 
Muito sugestiva é a metáfora usada por Stephen Stoer e Luisa Cortesão ${ }^{25}$ para intitular seu estudo sobre educação intercultural na escola: "Levantando a Pedra". Ao se observar a escola "de cima para baixo", a partir do ponto de vista burocrático e disciplinar, é como olhar um campo desertificado, cheio de grandes pedras, estéreis, impositoras de rotinas reprodutoras da improdutividade. Mas, ao se levantar aquelas pedras grandes, pode-se observar a efervescência de insetos que vivem e convivem na umidade do subsolo.

É este o nosso desafio educacional cotidiano: levantar as pedras que nos oprimem e deixar fluir a exuberância de vida e de relações que tecemos cotidianamente. É justamente o que Andréa Fetzner ${ }^{26}$ (2020) nos convida a valorizar no cotidiano escolar, mediante o enraizamento das experiências e propostas educativas - que são múltiplas, fluidas, transitórias, pequenas, microfísicas, micropolíticas - conectando-nos, pessoal e comunitariamente, com as culturas, epistêmes e éticas ancestrais capazes de potencializar as culturas populares, as culturas dos povos originários que constituem as nossas lutas no campo da educação popular, no aqui e no agora, em todos os lugares, conectando nossas singularidades ao todo - tal como nos convida o hino He Yama Yo e nos lembra Paulo Freire que, em sua última entrevista em vida, diz: "Eu gostaria de ser lembrado como um sujeito que amou profundamente o mundo e as pessoas, os bichos, as árvores, as águas, a vida!"

\section{Conclusão}

O conhecimento e o enfrentamento das fronteiras étnico-culturais e de exclusão nos colocam numa situação privilegiada para assumir novos desafios em vista de intensa e promissora educação para a cidadania e a construção da democracia. Nelas se percebe com maior acuidade a gravidade das consequências da crise global para a humanidade, sobretudo para

25 STOER, Stephen; CORTESÃO, Luiza. Levantando a pedra: da pedagogia inter-multicultural às políticas educativas numa época de transnacionalização. Porto: Afrontamento, 1999. 128p. (Biblioteca das Ciências do Homem. Ciência da Educação; 12).

26 FETZNER, Andréa Rosana (UNIRIO). A Contribuição das Pesquisas da Educação Popular. In: IX SEMINÁRIO INTERNACIONAL: FRONTEIRAS ÉTNICO-CULTURAIS E FRONTEIRAS DA EXCLUSÃO, 9, Campo Grande (MS), WEBINAR - IX Seminário Internacional: Fronteiras Étnico-Culturais e Fronteiras da Exclusão. Mesa-Redonda - Diferença, Democracia e Resistência: A Contribuição das Pesquisas Acadêmicas (30/10/2020). Campo Grande: UCDB, 2020. Disponível em: https://youtu.be/ ImTqcmJfFjs. Acesso em: 10 out. 2021. 
as classes populares e para o planeta em que vivemos, a "Pachamama". O autoritarismo, a necropolítica, o especismo, o racismo, as desigualdades sociais minam as lutas e conquistas democráticas, acelerando a corrida armamentista e o colapso ambienta, recrudescendo desafios existenciais urgentes para toda humanidade e para toda forma de vida em nosso planeta. $\mathrm{O}$ apelo para a reexistência faz-se necessário e urgente. Trata-se de um processo de reconstituição de estruturas de conexão, de vida, que vêm sendo geradas, cultivadas pelos povos originários ancestrais, portadores dessa sabedoria.

A busca da vida em plenitude, que vem sendo tecida, através dos tempos, pelas mais diferentes culturas ancestrais e por suas expressões religiosas, continua viva no coração da civilização moderna, apesar do sufocamento generalizado desse propósito essencial pelos jogos alienadores do mercado, da moda e da mídia. Daí que a proposta de uma educação libertadora deverá considerar a sabedoria dos povos ancestrais, que promove, para todos, condições de vida em plenitude, de Bem Viver. Reconhecer a cientificidade dos saberes dos povos originários, os saberes populares ancestrais, é um salto de qualidade na nossa forma de pensar, na nossa forma de produzir conhecimento, para vencer as necropolíticas, decolonizar as mentes, desconstruir o individualismo e potencializar a convivência harmoniosa entre todos os seres vivos que constituem nossa Mãe Natureza.

É este o nosso desafio educacional cotidiano: levantar as pedras que nos oprimem e deixar fluir a exuberância de vida e de relações que tecemos cotidianamente.

\section{Referências}

AGOSTINHO. Confissões. Trad. de J. Oliveira Santos, S.J. e A. Ambrósio de Pina, S.J. 1.ed. São Paulo: Victor Civita, 1973. p. 63 (Livro III, Capitulo 6, seção 11). Coleção Os Pensadores, vol. VI.

AMADO, Luiz Henrique Eloy (APIB). A Contribuição de Pesquisas de Indígenas e com Indígenas. In: IX SEMINÁRIO INTERNACIONAL: FRONTEIRAS ÉTNICO-CULTURAIS E FRONTEIRAS DA EXCLUSÃO, 9, Campo Grande (MS), WEBINAR - IX Seminário Internacional: Fronteiras Étnico-Culturais e Fronteiras da Exclusão. Mesa-Redonda - Diferença, Democracia e Resistência: A Contribuição das Pesquisas 
Acadêmicas (30/10/2020). Campo Grande: UCDB, 2020. Disponível em: https://youtu.be/ImTqcmJfFjs. Acesso em: 10 out. 2021.

ARTICULAÇÃO DOS POVOS INDÍGENAS DO BRASIL (APIB); AMAZON WATCH. Cumplicidade na destruição III: como corporações globais contribuem para violações de direitos dos povos indígenas da Amazônia Brasileira.APIB/AW, 2020. Disponível em: https://amazonwatch.org/assets/files/2020-cumplicidade-na-destruicao-3.pdf. Acesso em: 27 jul. 2021.

BATESON, G. Mente e Natureza. A unidade necessária. Trad. bras. Claudia Gerpe. Rio de Janeiro: Francisco Alves, 1986.

BHABHA, Homi. O local da cultura. Belo Horizonte: UFMG, 1998.

CNBB - Conferência Nacional dos Bispos do Brasil. Campanha da Fraternidade 2022: Texto-Base. Brasília: Edições CNBB, 2021.

EATON, George. Noam Chomsky: The world is at the most dangerous moment in human history. New Statesman. 17 September 2020. Disponível em: https://www.newstatesman.com/world/2020/09/noam-chomsky-world-most-dangerous-moment-human-history. Acesso em: 8 jan. 2021.

FELDENS, Dinamara (UFS). A Contribuição das Pesquisas de Gênero. In: IX SEMINÁRIO INTERNACIONAL: FRONTEIRAS ÉTNICO-CULTURAIS E FRONTEIRAS DA EXCLUSÃO, 9, Campo Grande (MS), WEBINAR - IX Seminário Internacional: Fronteiras Étnico-Culturais e Fronteiras da Exclusão. Mesa-Redonda - Diferença, Democracia e Resistência: A Contribuição das Pesquisas Acadêmicas (30/10/2020). Campo Grande: UCDB, 2020a. Disponível em: https:// youtu.be/ImTqcmJfFjs. Acesso em: 10 out. 2021.

FETZNER, Andréa Rosana (UNIRIO). A Contribuição das Pesquisas da Educação Popular. In: IX SEMINÁRIO INTERNACIONAL: FRONTEIRAS ÉTNICO-CULTURAIS E FRONTEIRAS DA EXCLUSÃO, 9, Campo Grande (MS), WEBINAR - IX Seminário Internacional: Fronteiras Étnico-Culturais e Fronteiras da Exclusão. Mesa-Redonda - Diferença, Democracia e Resistência: A Contribuição das Pesquisas Acadêmicas (30/10/2020). Campo Grande: UCDB, 2020. Disponível em: https://youtu.be/ImTqcmJfFjs. Acesso em: 10 out. 2021.

FLEURI, Reinaldo Matias (UFSC/UEPA). Intersecionalidade raça/etnia, gênero e classe como estratégia democrática e de análise científica das fronteiras étnico-culturais e da exclusão. In: IX SEMINÁRIO 
INTERNACIONAL: FRONTEIRAS ÉTNICO-CULTURAIS E FRONTEIRAS DA EXCLUSÃO, 9, Campo Grande (MS), WEBINAR - IX Seminário Internacional: Fronteiras Étnico-Culturais e Fronteiras da Exclusão. Conferência de Encerramento (30/10/2020). Campo Grande: UCDB, 2020a. Disponível em: https://youtu.be/0v3FNezP6i8. Acesso em: 8 jan. 2021.

FLEURI, Reinaldo Matias. Paulo Freire e as cosmovisões dos povos originários. In: Educazione Aperta, v. 7, 2020b, p. 242-261. Disponível em: https://educazioneaperta.it/archives/2828. Acesso em: 12 out. 2021.

GARCIA, Samuel Ruiz. Igreja e opção pelos pobres. In: FLEURI, Reinaldo Matias (org.). Movimento Popular, Política e Religião. São Paulo: Loyola, 1985.

GOMES, Aguinaldo Rodrigues (UNEMAT). A Perspectiva dos Movimentos de Gênero. In: IX SEMINÁRIO INTERNACIONAL: FRONTEIRAS ÉTNICO-CULTURAIS E FRONTEIRAS DA EXCLUSÃO, 9, Campo Grande (MS), WEBINAR - IX Seminário Internacional: Fronteiras Étnico-Culturais e Fronteiras da Exclusão. Mesa-Redonda Diferença, Democracia e Resistência: A Perspectiva dos Movimentos Sociais (29/10/2020). Campo Grande: UCDB, 2020. Disponível em: https://youtu.be/Q8OB_mISMNM. Acesso em: 10 out. 2021.

LOANGÓ, Anny Ocoró (CONICET-UNTREF). Diferença, democracia e resistência no contexto das fronteiras étnico-culturais e da exclusão. In: IX SEMINÁRIO INTERNACIONAL: FRONTEIRAS ÉTNICO-CULTURAIS E FRONTEIRAS DA EXCLUSÃO, 9, Campo Grande (MS), WEBINAR - IX Seminário Internacional: Fronteiras Étnico-Culturais e Fronteiras da Exclusão. Conferência de Abertura (28/10/2020). Campo Grande: UCDB, 2020. Disponível em: https://youtu.be/_yZNKSWUZ_s. Acesso em: 22 nov. 2021.

SCHILLING, Flavia Ines. Estudos sobre resistência. 1991. (257f). Dissertação (Mestrado) - Universidade Estadual de Campinas, Faculdade de Educação, Campinas, SP. Disponível em: https://doi.org/10.47749/T/ UNICAMP.1991.33204; http://www.repositorio.unicamp.br/Busca/ Download?codigoArquivo=457123. Acesso em: 22 nov. 2021 .

SISS, Ahyas (UFRRJ). Perspectiva do Movimento Social Negro. In: IX SEMINÁRIO INTERNACIONAL: FRONTEIRAS ÉTNICO-CULTURAIS E FRONTEIRAS DA EXCLUSÃO, 9, Campo Grande (MS), WEBINAR - IX Seminário Internacional: Fronteiras Étnico-Culturais 
e Fronteiras da Exclusão. Mesa-Redonda - Diferença, Democracia e Resistência: A Perspectiva dos Movimentos Sociais (29/10/2020). Campo Grande: UCDB, 2020. Disponível em: https://youtu.be/Q8OB_mISMNM. Acesso em: 10 out. 2021.

STOER, Stephen; CORTESÃO, Luiza. Levantando a pedra: da pedagogia inter-multicultural às políticas educativas numa época de transnacionalização. Porto: Afrontamento, 1999. 128p. (Biblioteca das ciências do homem. Ciência da Educação; 12).

WALSH, Catherine et al. Abertura do V Colóquio Internacional Diálogos Sul-Sul: O pensamento decolonial como instrumento de resistência: diferentes olhares. In: V COLÓQUIO INTERNACIONAL DIÁLOGOS SUL-SUL e II CONGRESSO INTERNACIONAL DE PESQUISA E PRÁTICAS EM EDUCAÇÃO (CONIPPE), Territórios e Fronteiras de vida em plenitude: desafios, propósitos e articulações atuais de raízes ancestrais. Mesa redonda: Catherine Walsh; Adrian Kethen Picanço Barbosa; Reinaldo Matias Fleuri (23/08/2021, 8h às 22h). TV-UFAC. Disponível em: https://youtu.be/Wfbz3kHKa9w. Acesso em: 10 out. 2021. 